\title{
El turismo en una comunidad maya yucateca: pasado, presente y un probable futuro
}

DOI: 10.22403/UQROOMX/TYP08/06

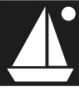

\author{
Elías M.Alcocer Puerto \\ Universidad de Oriente \\ Grace Lloyd Bascopé \\ University of North Texas \\ Nidelvia Vela Cano \\ Unidad de Culturas Populares-Yucatán
}

Resumen

Es común ver como cada año se incorporan numerosas grupos de comunidades indígenas a la actividad turística; sin embargo, hasta hoy no parece existir un mecanismo eficiente y de estructura local, que les permita ser partícipes directos de esa actividad económica. El presente trabajo muestra cómo la comunidad de Yaxunáh, del municipio de Yaxcabá, Yucatán, ha vivido su proceso de incorporación en la industria turística; se presenta desde el momento en el que se intentan familiarizar con el término "turismo", pasando por la construcción de infraestructura, el auge, el enfrentamiento de problemas relacionados con su organización social, el abandono del proyecto inicial y, ante todo, la actitud reflexiva de algunos de sus líderes y pobladores interesados en que el turismo sea una actividad económica que realmente beneficie a la comunidad.

\begin{tabular}{r|l} 
Palabras & Desarrollo local, organización social, proyectos sustentables, \\
Clave & $\begin{array}{l}\text { turismo rural, turismo solidario }\end{array}$
\end{tabular}

Correos electrónicos: alcocerpuerto@yahoo.com•gbascope@airmail.net,

•velacano@yahoo.com 


\section{Introducción}

Al iniciar el siglo XXI, el turismo se ha convertido en una importante fuente de capital económico para un gran número de países, principalmente por su efecto multiplicador y considerable derrama de dinero. México, dada su riqueza natural y cultural, se ha colocado en los primeros lugares en este tipo de servicio, por lo cual no resulta extraño encontrar en los planes de cada entidad federativa el impulso al desarrollo del turismo en poblaciones étnicas con atractivos susceptibles de ser transformados en un producto turístico.

De acuerdo con esta política pública, varias instancias, sobre todo gubernamentales y organizaciones civiles, han estimulado e implementado proyectos de desarrollo turístico en poblados indígenas. Estas acciones han propiciado que varias comunidades étnicas se vean envueltas por primera vez en proyectos turísticos; poblaciones que si bien obtienen beneficios inmediatos, en especial de carácter económico, también se enfrentan a mediano y largo plazos a nuevas problemáticas que repercuten en diferentes ámbitos de su vida local. De este contexto resalta la postura que han asumido algunos gestores, quienes por un lado omiten en los reportes o evaluaciones los conflictos que se producen, $y$ por el otro magnifican los beneficios de esos proyectos turísticos. Su actitud parcial, ambigua y contradictoria ha propiciado la minimización de los problemas de tipo social, político, económico y cultural que devienen de los proyectos en cuestión, afectando en la potencialidad de este tipo de actividades.

Así pues, el presente trabajo tiene como eje revisar de manera crítica los proyectos turísticos, con base en cuatro aspectos importantes y estrechamente vinculados entre sí:

I. El papel de las instancias externas a partir del respeto hacia el sistema social, cultural, económico y político de las localidades;

2. La capacitación suficiente y necesaria para los pobladores con el propósito de que éstos, en un futuro cercano, asuman la responsabilidad (planeación, administración y desarrollo) de esos proyectos;

3. El acercamiento de los locales con experiencias de otros grupos, considerando los problemas que han enfrentado y cómo los resolvieron; $y$

4. Proyectos viables que incluyan la participación activa, las expectativas y los valores de la población. 
De manera notable los puntos anteriores ponen en el flechero las acciones ya desarrolladas por algunas instancias externas en las comunidades indígenas, en particular las que han implementado proyectos turísticos en Yucatán. Este interés se suma a los diversos trabajos de carácter social que señalan que en proyectos de origen externo a las poblaciones receptoras que estuvieran basados en ideas y formas de organización diferentes a las de los grupos de base (locales), la mayoría de las veces chocan con las costumbres de las sociedades locales, creando a la larga problemas en la vida cotidiana de la población y en el seguimiento a mediano y largo plazos de la actividad turística (Rátz, 2000; PPD y PNUD-Pro-rural, 2005). Al respecto Brohman (1996) indica que, por lo general, en la implementación de sus propuestas, las instancias externas dedicadas a impulsar el turismo no prevén o dimensionan adecuadamente los efectos socioculturales en las localidades y menos aún visualizan que su presencia y actividad violentan las formas de organización, y los sistemas sociales y culturales de las comunidades, por ejemplo al ser un solo sector de la población el que se beneficie del turismo.

En ese contexto atisba la violencia simbólica y cultural (Bourdieu y Wacquant, 1995), surgiendo la urgente necesidad de revisar los apoyos económicos dirigidos a las comunidades tradicionales mayas, específicamente los vinculados con proyectos identificados como sustentables, partiendo del papel de las instancias externas e impulsoras de los proyectos turísticos. Sin embargo, tales instancias por lo general no están sensibilizadas para interactuar con grupos o culturas diferenciados, y previamente a los proyectos no se observa la realización seria de un diagnóstico cultural particularizado y exhaustivo; dos factores que repercuten en la planeación de un proyecto turístico integral y comunitario que incluya el interés de la población el análisis en conjunto de los beneficios y riesgos que enfrentarían y, además de la capacitación acorde a la realidad local, estudios económicos y de mercado.

Ese tipo de conflictos se puede localizar en la Península de Yucatán, particularmente en los proyectos turísticos impulsados en determinadas comunidades mayas. Por ejemplo, el proyecto turístico del cenote de Dzinup,Valladolid, Yucatán, que, debido a los conflictos internos, en los últimos años la Secretaría de Turismo local está administrando. Partiendo de la problemática expuesta, el presente artículo tiene como propósito llamar la atención sobre la forma como se están desarrollando los denominados proyectos sustentables en las comunidades mayas $y$, sobre todo, resaltar sus efectos en la vida social y cultural local. 
Por último, a partir de la experiencia de un grupo local se plantean acciones que influyan en la potencialización de los proyectos turísticos mayas, destacando la importancia de la participación activa de los pobladores. No obstante el número de poblaciones mayas yucatecas dedicadas a la actividad turística, en este documento se toma como ejemplo parte de lo encontrado en una serie de investigaciones y en el trabajo etnográfico, que abarcan dos décadas de trabajo de campo en la comunidad maya de Yaxunáh, comisaria del municipio de Yaxcabá,Yucatán, México.

La comunidad se encuentra ubicada en el extremo centro sur del estado de Yucatán, justo a 20 kilómetros al sur de la zona arqueológica de Chichén Itzá. En este espacio geográfico y poblacional se estudió el cambio en la organización local propiciado principalmente por la actividad turística, utilizando el método etnográfico descrito por Spradley (1980), Taylor y Bodgan (1996) y Mayan (200l), en el cual prevalece el dato cualitativo con análisis de tipo interpretativo. La recolección de datos involucró la observación y descripción sistematizada, así como pláticas informales y entrevistas abiertas y semiabiertas a la población en general, $y$ de manera exhaustiva a los pobladores directamente vinculados con la actividad del turismo; esto permitió que se partiera de una visión general de la comunidad y después se profundizara en el tema turístico y artesanal por medio de los integrantes de comités, grupos e informantes clave.

Este ensayo sintetiza los resultados del trabajo etnográfico realizado en Yaxunáh de la década de 1990 al presente. En general, resaltan la visión y las acciones de esta población hacia un proyecto turístico, y en particular, la conducta de los grupos organizados que interactuaron con las instancias externas promotoras y gestoras del desarrollo del turismo en la localidad. Para comprender este fenómeno social y cultural se ofrece, inicialmente, un panorama de cómo esta comunidad maya se familiarizó con el concepto de turismo. Enseguida se dan datos de la materialización y desarrollo del proyecto turístico, marcando en cada etapa algunos de los problemas locales que se fueron presentando. Finalmente se brinda información relativa al abandono del proyecto original y la actitud reflexiva de los líderes y una parte importante de la gente local sobre esa experiencia, condición que los ha dirigido a retomar la actividad turística, pero replanteándose cómo quieren trabajar el turismo y en qué términos desarrollarlo, emanando de esta inquietud la decisión de que en la nueva fase contarán con la colaboración de instancias externas, pero sin depender de ellas. 


\section{Resultados}

En Yaxunáh, la idea de trabajar en el turismo data de finales de la década de 1980 y está estrechamente vinculada con el trabajo de un grupo de arqueólogos estadounidenses, en la zona arqueológica de esta población. Sin embargo, la incorporación a la actividad turística ocurrió a finales de los noventa, por medio de un proyecto de desarrollo impulsado por una organización no gubernamental (ONG), la cual inicialmente realizó actividades de convencimiento con la gente local para que participara, $y$ a quienes decidieron participar en el proyecto les brindó pláticas o capacitación en las que se ponderaban los beneficios económicos que les traería el turismo.

Desde tiempo atrás,Yaxunáh ha estado regida por el sistema ejidal o de tenencia comunal de la tierra. Su máxima autoridad interna la constituye la asamblea ejidal, cuyas funciones han sido la reglamentación de las actividades sociales, la organización del trabajo comunitario, la regulación de las fajinas, la ayuda mutua, la distribución de las tierras agrícolas y, a partir de 1989, la repartición del empleo local ofrecido por instancias externas. De esta manera, su sistema organizacional contribuía a la solidaridad y al beneficio comunitario, reflejado en la colaboración en la milpa, el traslado de los enfermos, o haciendo la fajina de limpieza y mantenimiento de la comunidad. La importancia de la asamblea en la estabilidad social se puede ejemplificar con la decisión que tomó en la década de 1950, de prohibir la venta de licor en el interior de la comunidad, reglamentación que, con algunas modificaciones, persiste hasta la actualidad.

Esta población bilingüe (maya-español) tiene una organización social y económica estrechamente ligada a la producción agrícola, actividad económica que en décadas pasadas satisfacía a los pobladores en su necesidad alimentaria y además les otorgaba un cierto remanente de dinero que era utilizado para adquirir otros productos de manufactura externa. Empero hoy en día, aunque prevalece el trabajo en la milpa, su producción es primordialmente para el consumo familiar, y si se busca obtener un excedente económico los miembros de la familia requieren llevar a cabo otras actividades, por ejemplo el trabajo artesanal o emplearse como albañiles sobre todo en las ciudades de Mérida, Piste, Valladolid o Cancún.

La población cuenta con un ejido que tiene múltiples recursos tanto naturales como culturales, además de una zona arqueológica de mediana dimensión, un sak bej de 100 kilómetros que la conecta con la ciudad prehispánica de Cobá; 
dos cenotes; dos haciendas coloniales, propiedades de un tranquilo y pintoresco poblado donde se realizan ceremonias agrícolas (Cha'a chac, janli kool), sociales (Jets mek) y culturales (gremios, Janal Pixan); entre otros elementos catalogados como recursos susceptibles de ser utilizados turísticamente.

Quizá por las características naturales, sociales, culturales y económicas de Yaxunáh, y a raíz de la interacción de la población con un grupo de arqueólogos extranjeros, en 1986 surgió la idea de emplearlas como atractivos turísticos, lo cual a los pobladores les pareció atractivo dado que se imaginaban que en el futuro podrían ser guías de turistas, como ya acontecía en otras zonas arqueológicas de Yucatán.

En tanto germinaba la idea del turismo, la asamblea ejidal continuó dirigiendo la vida social y económica de la población durante varios años. Por ejemplo, en 1988, justo después del paso del huracán Gilberto, varios ejidatarios se vieron obligados a emigrar a centros turísticos de la región, hecho que influyó en que la asamblea ejidal negociará con los arqueólogos extranjeros que todos los ejidatarios fueran contratados mediante un sistema rotativo en el trabajo de la zona arqueológica. Este sistema se apegaba a la noción consensuada del beneficio comunitario, no obstante eran excluidos quienes no estaban afiliados al sistema ejidal. Aun así, la rotación laboral de los ejidatarios se mantuvo hasta 1996, la cual fue modificada con la salida de los arqueólogos extranjeros y la entrada de arqueólogos del Instituto Nacional de Antropología e Historia (INAH).

Tal situación condujo a que la asamblea ejidal presionara al Instituto para que se respetara el sistema rotativo de trabajo previamente establecido, logrando que, con ciertas modificaciones, se mantuviera ese sistema hasta $200 \mathrm{I}$. Esta rotación laboral repercutía notablemente en las economías familiares y en el descenso de la emigración laboral.

La salida de los arqueólogos extranjeros también coincidió con la entrada de una ONG yucateca que promovió especialmente la actividad artesanal entre las mujeres adultas de la localidad, enunciando que ésta brindaría beneficios comunitarios para la población. Después de la etapa de convencimiento, la ONG agrupó a las interesadas en tres comités, y fueron capacitadas en el trabajo artesanal del bordado y en la talla de madera, con el fin de satisfacer el mercado turístico, tanto externo como posiblemente interno. La actividad artesanal fue aceptada por las mujeres, en gran parte por el beneficio económico que traería a su ingreso familiar, como testimonia una de las participantes: 
entré al grupo por el trabajo que nos dijeron es bueno, [ya] que nos dijeron que nos van a enseñar a diseñar figura. Pero como es para vender, yo lo pensé, es un poco de dinero para la familia; la gente lo necesita [esposa de un ejidatario y participante de uno de los comités artesanales, 2005].

Cabe mencionar que los comités organizados por la ONG se caracterizaron por estar conformados por personas de diferentes familias, a decir de la instancia promotora, para evitar el nepotismo. No obstante, con el tiempo estos comités se fueron depurando y finalmente quedaron grupos más pequeños de entre diez y I 5 personas en los que dominaron las familias extendidas, el parentesco político y las relaciones de amistad, recuperándose así la forma de agrupación que dominaba previamente en la localidad.

Los resultados de esta acción dirigida a las mujeres se pueden resumir en lo siguiente: Se otorgó un beneficio económico familiar mediante el trabajo femenino, pero al mismo tiempo, a partir de este ingreso, las artesanas empezaron a incursionar en los espacios públicos y con ello a obtener un mayor estatus social local, dado que comenzaron a visibilizarse en la vida pública y a salir de la población, sin la compañía forzosa de algún hombre. Un denominador importante de resaltar es que la capacitación artesanal recibida por las mujeres, en especial en el tallado de madera, propició un efecto multiplicador, ya que ellas capacitaban a sus maridos, hijos y demás familiares para que ayudaran en la producción artesanal. Como la ONG privilegiaba la mano de obra femenina, fueron notorios los casos en los que las señoras hacían pasar como suyos productos artesanales realizados por sus esposos u otros familiares. En este acontecer social y cultural transciende que la ONG impulsó un proceso económico en las mujeres, pero éste trajo otros cambios, como la participación femenina en la vida pública de la localidad, aunque, siguiendo el sistema familiar dominante en la localidad, las mujeres involucraron a los demás miembros de la familia. Al respecto vale comentar que dicho cambio no fue mal visto por la mayoría de los habitantes, incluso por los hombres.

Fue hasta 1998 cuando la ONG realizó un diagnóstico con el cual sustentó su idea de que la comunidad tenía un potencial turístico, aspecto que podía servir como base del desarrollo comunitario. Al respecto un informante comentó:

Desde atrás [antes] de la (ONG) estaban los gringos que nos dio la idea de [l] trabajo, de un hospedaje turístico, desde que estaban los arqueólogos extranjeros. Y cuando la [ONG] hicieron los talleres diagnósticos y ya después de esos diagnósticos que hicieron llegaron a conclusión y vimos 
que [el] primero era un hospedaje para los visitantes y [el] segundo para las artesanías, porque hay señoras que saben bordar y tallar madera y necesitan más capacitación [ejidatario, miembro del comité turístico, 2004].

Para finales de 1999, la ONG obtuvo un financiamiento de más de 230000 dólares' para desarrollar en tres años un proyecto de desarrollo basado en el turismo, que contenía también aspectos de apoyo a los grupos organizados de artesanas, la formación de promotores comunitarios, reforestación y programas de siembra de hortalizas y crianza de aves para mejorar la alimentación local.

Como parte del proyecto turístico, ese mismo año, la ONG de nuevo convocó a la población a formar un comité que trabajara exclusivamente la parte turística del proyecto, a lo que respondieron sólo una docena de ejidatarios, mientras los otros no participaron porque pensaban que al aceptar incorporarse a dicho comité perderían su trabajo en la zona arqueológica con el INAH, ya que el nuevo proyecto requeriría actividades que ocupaban la mayor parte del día laboral, pero sobre todo no participaron porque no tenían claro a qué se tenían que comprometer. Uno de los ejidatarios participantes señaló:

De por sí nosotros queríamos que haya [el proyecto] porque sabíamos más o menos el trabajo para el servicio de los turistas y por eso nos apuntamos inmediatamente para ese trabajo. La gente no conocía ese tipo de trabajo. Ellos [los demás ejidatarios] pensaban que iban a robarlos o algo que no estaba bien. Pensaban que iban a perder su trabajo en las ruinas [zona arqueológica] [ejidatario, miembro del comité turístico, 2005].

A este nuevo comité le tocó teóricamente administrar el negocio turístico en estrecha colaboración con la ONG.A pesar del proceso con el que se constituyó este comité, surgieron varias divisiones y dudas entre la gente de la comunidad, en esencia porque ese proyecto no contemplaba la rotación de empleos, y la participación de la asamblea de ejidatarios era cada vez menor. ong indicó que la ausencia de la asamblea en este comité se debió a que consideró que era mejor trabajar la parte turística con un número reducido de ejidatarios; interés que determinó que únicamente los integrantes de este comité recibieran capacitación sobre cómo administrar las primeras seis cabañas y una cocinacomedor que fueron restauradas y construidas ${ }^{2}$ para iniciar el proyecto.

Cantidad equivalente a más de 2000 dólares por cada familia de la comunidad.

${ }^{2}$ Dicha construcción se hizo en un terreno donde ya existían unas antiguas cabañas que fueron anteriormente utilizadas por los arqueólogos estadounidenses durante sus diversas estancias en la comuni- 
La capacitación otorgada al comité turístico, además de administración, incluyó el trato al turista, cocina, higiene y mantenimiento de las instalaciones. Sin embargo la ONG, por medio de su personal externo, supervisaba y llevaba el control de la mayor parte de las actividades del comité turístico y era la encargada de realizar los proyectos, lo que estableció un vínculo más directo entre la ONG y el comité turístico, sin que interviniera la asamblea ejidal. Posiblemente por la ausencia de esta última, el comité repartía la mayor parte de las ganancias entre sus miembros y en pocas ocasiones las destinó al mantenimiento o ampliación de sus instalaciones o a alguna mejora para la población. Incluso se tienen datos de que en numerosas ocasiones recurrió al ayuntamiento local para pedir ayuda en el pago de la corriente eléctrica o para ampliar la infraestructura a su cargo.

En el desarrollo del proyecto, dada la demanda turística, el resto de los pobladores externaron su inconformidad por no recibir beneficios y porque consideraban que el proyecto turístico no era comunitario, ya que las entradas económicas se concentraban únicamente en los integrantes del comité turístico. Sus argumentos se basaban en que, aunque estaban conscientes de que al principio habían decidido no trabajar en el proyecto, creían que tenían derecho a trabajar en el turismo, ya que los recursos mostrados a los turistas también les pertenecían. Este malestar fue de tal magnitud que en una ocasión un pequeño grupo llegó a lanzar una amenaza velada de sacar a la ONG y destruir todo lo que habían construido. Uno de los pobladores, que además fue comisario, mencionó:

Se dijo que era comunitario, pues así fue la idea, pero más cuando empezó a funcionar ese proyecto, no así salió como ellos dijeron, por eso la gente estaba desanimada. Por ejemplo, dijeron que [el comité turístico] es beneficio de la gente, beneficio de la comunidad, mejor dicho en beneficio personal, así sale, así se ve.

Otro de los informantes, no miembro de los comités, expresó lo siguiente:

Dijeron que cuando se aprobara ese proyecto, todos (se) van a beneficiar y pensaron que cuando se aprueba ese proyecto van a trabajar todos, como las ruinas zona arqueológica], pero cuando llegó [el proyecto turístico] ya no lo hicieron así.

La ONG escribió otros proyectos para incluir a otros pobladores en los servicios turísticos, con el propósito de mitigar la manifiesta inconformidad. En 2002 la asociación civil consiguió financiamiento de la Comisión Nacional para 
el Desarrollo de los Pueblos Indígenas (CDI) con objeto de formar dos comités más, cuya idea era que los ejidatarios restantes (más de 100) participaran y se beneficiaran del turismo. Esto motivó la creación de otros dos grupos, uno para administrar el cenote ${ }^{3}$ localizado en el centro de la población, y otro para atender un sendero con otros cenotes. El primero empezó con 56 ejidatarios interesados y al año de su formación sólo contaba con 12 participantes, por lo que se disolvió en agosto de 2009; mientras que el segundo comenzó a funcionar con 48 miembros, un año después únicamente quedaron diez y se disolvió a los dos años de haberse conformado.

Cabe apuntar que en estos dos comités se observó un alto grado de desorganización y poca capacitación sobre estos nuevos trabajos, al grado de que la mayoría de las personas involucradas veía estas labores como temporales, por lo que al agotarse el financiamiento de la CDI, casi todos los integrantes de los nuevos comités se desligaron y siguieron con sus actividades artesanales.

La ONG mantuvo su interés por llevar más proyectos a la localidad para proporcionarle empleo a sus habitantes; sin embargo, sus propuestas no fueron financiadas y no se llevaron a cabo. Sobre este suceso, la gente local tiene la impresión de que esos proyectos no fueron aprobados porque los anteriores no habían sido exitosos.

Pese a los esfuerzos de la ONG, el descontento de la gente continuó, ya que el primer comité turístico continuaba no dando cuentas claras y no compartía los beneficios económicos con el resto de los pobladores. No obstante, en ese lapso otorgaba servicios de alquiler de las cabañas y de comida a los turistas, además de que permitía la entrada a este lugar a los parientes de sus integrantes para vender artesanías (bordado y tallado de madera), en tanto este espacio estaba restringido para la venta de los productos de los otros artesanos. La conjunción de estos factores trajo consigo un desprestigio de la ONG y un notable malestar hacia el proyecto turístico.

En medio de esos conflictos locales, entre 2001 y 2004 se recibieron numerosos grupos de turistas en la comunidad, que fueron atendidos por el comité turístico y la ONG. Los grupos de turistas estaban conformados sobre todo por estudiantes y voluntarios que pagaban alrededor de 45 dólares por su

\footnotetext{
${ }^{3}$ Manantial natural de agua alimentado por corrientes subterráneas, comúnmente encontrado al norte de la Península de Yucatán.
} 
estancia y comida diaria. Su itinerario incluía, además de conocer los atractivos culturales y naturales del lugar, ofrecer algún tipo de trabajo voluntario, como pintar escuelas, hacer pisos de cemento, limpiar áreas públicas o dar clases de inglés a niños y jóvenes.

Este trabajo voluntario de los turistas, identificado como turismo solidario, era bien visto por la comunidad, e incluso, derivado de ese contacto, se consolidó un grupo de jóvenes locales voluntarios que hasta el día de hoy existe y se dedica a realizar actividades de reciclaje y educación ambiental en la población; de hecho, varios adultos que no formaban parte del proyecto turísticos están convencidos de los beneficios de la labor de los jóvenes y han colaborado en esta clase de trabajo.

Dada la aceptación de este tipo de turismo, el comité, en un intento por justificarse, lo señalaba como parte de su contribución al beneficio común, afirmación que fue debatida por los demás pobladores ya que los inconformes sentían que la aportación del comité debía ser otra, más concreta y directa. Esta poca claridad en el beneficio para la comunidad y el descontento en general fueron del conocimiento de los turistas, lo que contribuyó al desprestigio y caída de la actividad turística, dado que éstos optaron por no regresar o no recomendar el lugar.

Otra repercusión del descontento fue el abandono de la fajina, trabajo no remunerado destinado a la limpieza de las áreas públicas:

Si muchos van a hacer limpieza y fajina de la escuela el domingo, ya no tienen tiempo de hacer la del centro [del poblado. Cuando un domingo hay grupos [de turistas] los [miembros de los] comités ya no salen y están ganando. La gente se dio cuenta y dice que ellos [los de los comités] deben hacer el trabajo y no nosotros.Allá empiezan los rumores de que no van a salir a hacer sus fajinas [ejidatario y ex comisario municipal, 2005].

Con esas condiciones a partir de finales de 2004 la actividad turística bajó considerablemente, en parte por el desprestigio al que estuvo expuesta y porque terminó el financiamiento del proyecto. Al mismo tiempo, la ONG comenzó a tener problemas internos y terminó por retirarse un tiempo de la comunidad pero apoyando de una manera discreta a los comités formados. En 2005 intentó regresar con un nuevo proyecto de apoyo al turismo, pero en una asamblea la mayoría de los ejidatarios se opuso, argumentando que esos proyectos realmente sólo beneficiaban a unos cuantos y no a toda la comunidad. Por esta reacción, la ONG decidió retirarse permanentemente de la localidad. 
Después de su salida, los comités que organizó en la comunidad comenzaron a decaer aún más.Algunos de sus integrantes se volvieron a reunir eventualmente, aprovechando su constitución formal para solicitar apoyos económicos o vender como grupo étnico sus servicios o productos artesanales. Por su parte, en la población abunda el trabajo del tallado de madera, (predominando la organización basada en la familia extensa), tanto que, en el presente, es la actividad económica que más ingresos da a la comunidad, puesto que involucra a más de 80 por ciento de las familias locales. Cabe mencionar que el éxito de esta actividad está vinculado con la desforestación de la materia prima en el ejido, el chaca.

En cuanto al comité turístico, las instalaciones de las cabañas y el comedor han estado en franco deterioro, incluso algunas de ellas hoy están inutilizables. Aunado a esto, el comité turístico busca la forma de vender las instalaciones que, en teoría, la comunidad le había entregado en préstamo. Se sabe por fuentes locales que el comité ha tramitado documentos legales que le podrían dar el grado de propiedad privada del terreno donde están asentadas las cabañas y el restaurante turístico, lo que le permitiría venderlos a personas externas a la comunidad. Por esta pretensión, la comunidad y en particular la asamblea de ejidatarios están inconformes, ya que, según sus estatutos internos, no se debe vender terrenos a personas de fuera, $y$ mucho menos estas instalaciones que fueron hechas con dinero proveniente de los proyectos. El terreno y las instalaciones que están a cargo de este comité se encuentran en la actualidad en litigio.

Otra preocupación por un terreno público o comunitario la constituye el cenote del centro de la localidad, el cual desde 2002 estuvo en manos de un comité. Como ya se mencionó, también fue formado por la ONG,y en el ejercicio de administrarlo restringía la entrada a las personas de la localidad. Después de varios años de negociación, en agosto de 2009 los integrantes de este comité accedieron a devolver el terreno donde está el cenote. Ahora, la comunidad, en voz de sus autoridades, dice que pretende tener más cuidado al momento de prestar estos terrenos y también ha manifestado que vigilará que sean administrados de una manera diferente, en la cual la gente sienta que realmente son de todos y que tienen el control sobre ellos.

En un intento de la población de Yaxunáh de retomar el proyecto turístico se ha planteado la necesidad de definirlo de forma conjunta, consensuada $y$ 
congruentemente con su manera de hacer y pensar las cosas, donde prevalezcan oportunidades equitativas de empleo generado por el turismo u otras formas de trabajo; acceso a los locales en los recursos naturales y materiales como el cenote, la zona arqueológica, el sendero, etc.; $y$, ante todo, una venta justa y equitativa de sus productos artesanales.

Con relación al interés señalado en el párrafo anterior, en julio de 2009 se creó un Consejo Comunitario, integrado por ocho personas provenientes de diversos sectores o rumbos del pueblo. Este nuevo Consejo, a partir de la experiencia de los comités promovidos por la ONG, determinó que se definiría por ser de carácter rotativo (cambio paulatino de los integrantes cada dos años) y estaría constituido por representantes de diferentes sectores de la población y por las autoridades en turno. Especificó que una de sus funciones principales radicaría en reestructurar el modo en que la comunidad quiere aprovechar sus recursos naturales y culturales. Como primer paso para retomar el proyecto turístico, este Consejo se ha planteado la conformación de un Centro Cultural Comunitario, donde se congregue la experiencia local y se tomen decisiones 0 se dé capacitación efectiva acorde a la realidad local, que ayuden a consolidar a mediano y largo plazo los anhelos de tener un trabajo estable y justo en la misma comunidad, y a la par se vele por el uso racional de los recursos arqueológicos, naturales y culturales.

\section{Discusión}

La incursión de Yaxunáh en la industria turística fue una idea inducida por instancias externas, encabezadas por una ONG, aprovechando las condiciones naturales, culturales y arqueológicas para desarrollar tal actividad, además de que la gente estaba animada por aprender y participar en este tipo de proyectos, pero de acuerdo a sus sistemas locales, aspecto que no contempló la gestora, aun cuando realizó un diagnóstico. Esta situación parece ser recurrente en varios casos (Rátz, 2000; PPD/PNUD-Pro-rural, 2005), que se han expuesto en otras investigaciones, y que proponen podría subsanarse, estudiando previamente la organización social y las aspiraciones de la localidad, y a partir de este conocimiento sacar parámetros para desarrollar los proyectos. Esto evidentemente va en contra del tiempo y de los propósitos de implementar en las comunidades mayas modelos exitosos de otros lugares. 
Al respecto, autores como Norris et al. (1998) recomiendan que para alcanzar el éxito en este tipo de proyectos, es importante la asesoría de las ONG, siempre y cuando tengan clara su función de ser impulsoras de procesos, lo cual implica la exclusión de lazos de dependencia. Alcanzar este nivel es difícil, dado que otros autores señalan que a veces las instancias externas procuran la creación de lazos de dependencia porque con esto aseguran la obtención de apoyos económicos de fondos o fundaciones nacionales e internacionales que apoyan al desarrollo de proyectos en comunidades necesitadas (Butler y Hinch, 1996; Martínez Novo, 2006). Igualmente se ha indicado que las instancias externas se encuentran con un factor limitante que en gran medida establecen las fundaciones patrocinadoras de proyectos, además del espacio de éstos y sus temas: su temporalidad, lo cual en muchos casos condiciona el tiempo de trabajo de las gestoras en las comunidades, $y$ las obliga a prescindir del trabajo que conlleva un largo plazo, repercutiendo en la falta de respeto a la dinámica y tiempos de las mismas (Malena, 1995; PPD/PNUD-Pro-rural, 2005).

En relación con el párrafo anterior, en el caso que se revisó se puede extrapolar que la ONG, relegó la participación de la asamblea y trabajó directamente con comités o grupos de la comunidad porque esto le garantizaba terminar el proyecto de acuerdo a lo establecido con su patrocinadora, además de cumplir con el requisito de ésta de desarrollar proyectos mediante la creación de comités locales, con la finalidad de propiciar el beneficio comunitario. Evidentemente, la conformación de comités con un modelo externo pasó por alto las reglamentaciones internas de la comunidad, que otorgaban un alto grado de respeto a la asamblea ejidal y que marcaban la rotación de los empleos. Esta omisión resultó contraproducente, ya que a la instancia externa le creó conflictos con los locales y condujo a un clima de descontento entre los pobladores por considerar este tipo de organización como injusto e inequitativo.

Asimismo en el caso expuesto, se notó la forma persistente en la que se dio la relación entre los comités y la ONG, pues aunque la gente local estaba organizada en comités de trabajo y tomaba ciertas decisiones internas, la mayoría de las decisiones importantes fueron tomadas por la ONG. Es cierto que ella proveyó capacitación, pero aparentemente no fue suficiente, ya que terminó haciendo ella misma los procesos más relevantes del proyecto y generó que un selecto grupo se apropiara de los beneficios económicos. Esta situación no es un caso aislado; también se ha reportado que ha ocurrido en otros lugares (Pretty, 1995, cit. por Mowforth y Munt, 1998: 24I). 
En cuanto a las mujeres de los comités, a partir de las acciones de la ONG, fue evidente que estuvieron inmersas en un proceso de resocialización (Berger y Luckmann, 1968; Krotz, 1997), ya que aprendieron una nueva forma de organizarse y se adentraron en técnicas artesanales que les redundó en un mayor ingreso económico y en un papel más activo en su sociedad. Mujeres que también destacan porque al compartir sus nuevos conocimientos con sus familiares, independientemente del genero y la generación, refuncionalizaron su adiestramiento artesanal, es decir lo adaptaron al sistema local que establece el trabajo con los familiares y amistades cercanas. Siguiendo a Tsing (2005), vemos que la respuesta de Yaxunáh es una muestra de la facultad de las comunidades anfitrionas para responder a las acciones impuestas a su dinámica cultural por instancias externas, hecho que al mismo tiempo nos encamina a señalar que la comunidad en cuestión no se encuentra cerrada a los cambios, al contrario, está abierta a ellos, pero tratando de mantener su singularidad cultural.

El contexto turístico ofrecido por Yaxunáh muestra una situación contradictoria: por una parte, los turistas de tipo solidario apoyan el beneficio comunitario, aspecto que previamente al proyecto turístico prevalecía en el sistema social de la comunidad; por la otra, el éxito del proyecto turístico se sustentaba en el beneficio comunitario, el cual fue fragmentado por el mismo proyecto.

\section{Conclusiones}

Con los datos presentados resulta evidente que, en los últimos 20 años, Yaxunáh ha pasado de ser una comunidad basada en la agricultura con fuertes tendencias comunitarias, a ser hoy día una comunidad productora de artesanías de madera, aunque sigue practicando la agricultura pero netamente de subsistencia.

Desde la perspectiva de los investigadores, la problemática encontrada en la comunidad tuvo su origen en el desconocimiento u omisión de las formas organizacionales locales, en las diferencias en torno a la concepción del beneficio comunitario, en una falta de planeación con la comunidad, en una comunicación deficiente y en la falta de capacitación ajustada a una realidad local por parte de las instancias externas. Estos factores incidieron en que los pobladores no conocieran ni comprendieran desde el inicio y durante el proyecto, las diversas etapas y ámbitos de la actividad turística a profundidad, como tampoco permitieron que se sembrara en ellos las condiciones para que fueran autónomos y 
capaces de tomar el control del proyecto cuando la ONG se fuera de la localidad. Contrariamente, trajo como consecuencia que al agotarse el dinero del proyecto, también las actividades inherentes a él decayeran, pero manteniéndose los conflictos e insatisfacciones de los habitantes.

Los factores mencionados también propiciaron que el proyecto beneficiara mayormente a los involucrados en el primer comité turístico, grupo que controló los beneficios y excluyó a otros sectores de la comunidad, transgrediendo con su actitud la noción local de beneficio comunitario. Este hecho nos conduce a un conflicto derivado entre la forma como esta población entiende el beneficio comunitario y la de la ONG, diferencias que, a nuestra consideración, deben ser tenidas en cuenta en los proyectos impulsados por instancias externas. Igualmente se observó que la manera en la que se desarrolló el proyecto repercutió en la cohesión y solidaridad comunitaria, generando la pérdida del atractivo cultural étnico y solidario del proyecto turístico.

Hay que destacar que el trabajo de la oNG hizo posible la toma de conciencia de los pobladores sobre lo complejo que son los proyectos turísticos y que son una pieza medular en ese tipo de iniciativas. También fueron patentes los beneficios femeninos que conllevó el proyecto turístico: económicos, sociales y culturales.

No obstante los retos que ha enfrentado la comunidad de Yaxunáh, se puede observar que, a partir de su experiencia, ahora se replantea la forma en la que quiere actuar dentro de la industria turística:primero, pretende organizarse internamente de acuerdo a sus normas locales, pero no contraviniendo las leyes estatales o federales, o sea con una actitud incluyente. También se traza la necesidad de capacitarse y de crear un Centro Cultural Comunitario, manejado por la gente local desde su propia perspectiva y ritmo. Esta actitud nos lleva al señalamiento de que la comunidad está en la búsqueda de un presente y un futuro planificados por ellos mismos, acción que debería ser tomada en consideración en los proyectos turísticos en general. Si Yaxunáh está abierta a la interculturalidad, ¿por qué los gestores no la llevan a cabo?

Por último es importante señalar que lo expuesto en el presente artículo sobre lo sucedido en la comunidad mencionada, de ningún modo representa una generalidad de casos en Yucatán, sin embargo y con base en la experiencia de los autores, puede decirse categóricamente que al revisar los casos de otros proyectos comparten un número considerable de situaciones.A partir de 
esta experiencia es que este trabajo constituye un llamado de atención hacia la comunidad de investigadores, instancias gubernamentales y organizaciones no gubernamentales para que reflexionen en torno a su trabajo en las comunidades, en especial en los proyectos turísticos, negocio que promete ser lucrativo y beneficioso para las localidades indígenas.

\section{FUENTES CONSULTADAS}

Berger, Peter L.y Thomas Luckmann (1968). La construcción social de la realidad. Buenos Aires:Amorrortu.

Bourdieu, Pierre (1990). “Espacio social y génesis de las clases”, en Sociología y cultura. México: Consejo Nacional para la Cultura y las Artes/Grijalbo, 28I-309.

Bourdieu, Pierre y Loïc J.D.Wacquant (I995). Respuestas. Por una antropología reflexiva. México: Grijalbo.

Brohman, John (1996). "New Directions in Tourism for Third World Development". Annal of Tourism Research, 23 (I), 48-70.

Butler, Richard y Thomas Hinch (eds.) (1996). Tourism and Indigenous People. Londres: International Thomson Business Press.

Krotz, Esteban (1997). "Cambios culturales y procesos de re-enculturación”, en E. Krotz (ed.). Cambio cultural y resocialización en Yucatán. Mérida: Ediciones de la Universidad Autónoma de Yucatán, 17-38.

Malena, Carmen (1995). Working with NGOs.A Practical Guide to Operational Collaboration between The World Bank and Non-governmental Organizations. Washington, D.C.: Operations Policy Department, World Bank.

Martínez Novo, Carmen (2006). Who Defines Indigenous?: Identities, Development, Intellectuals and the State in Northern Mexico. New Brunswick: Rutgers University Press.

Mayan, María J. (200I). Una introducción a los métodos cualitativos: Módulo de Entrenamiento para Estudiantes y Profesionales. Traducción al español de César Cisneros Puebla. México y Edmonton: Universidad Autónoma Metropolitana-Iztapalapa/Qual Institute Press.

Norris, Ruth,J.ScottWibwe y Luis Oswaldo Morales Marín (1998).“CommunityBased Ecotourismo in the Maya Forest: Problema and Potencials", en R.B. Primack et al. (eds.). Timber, Tourism and Tempers. Conservation 
and Development in the Maya Forests of Belize, Guatemala and Mexico. Washington, D.C.: Island Press, 327-363.

PPD/PNUD-Pro-rural (2005). Programa de Pequeñas Donaciones. Memoria de Proyectos. Año 4 - Fase Operacional II. Bolivia: Fondo para el Medio Ambiente Mundial (FMAM)/Programa de las Naciones Unidas para el Desarrollo (PNUD)/Programa de Pequeñas Donaciones (PPD-Bolivia). Pretty, Jules (1995). Regerationg Agriculture: Polices and Practice for Sustainability and Self-Reliance. Washington, D.C.: Earthscan.

Rátz, Tamara (2000). "Residents' Perceptions of the Socio-cultural Impacts of Tourism at Lake Balaton, Hungary”, en G. Richards y D. Hall (eds.). Tourism and Sustainable Community Development. Nueva York: Routledge, 36-47.

Spradley, James P. (1980). Participant Observation. Orlando: Holt, Rinehard and Winston.

Taylor, Steve J.y Robert Bogdan (1996). Instrucción a los métodos cualitativos de investigación. Barcelona: Paidós.

Tsing, Ana L. (2005). Friction. An Ethnography of Global Connections. Princeton: Princeton University Press 